\title{
DESENVOLVIMENTO DE UM DESTILADOR SOLAR TIPO ESCADA E ANÁLISE DE DESEMPENHO EM RELAÇÃO A UM DESTILADOR SOLAR COM COBERTURA PIRAMIDAL
}

\author{
A. B. L. SPIRANDELI ${ }^{1}$, G. O. PRADO ${ }^{2}$ e N. G. SOUSA ${ }^{1}$ \\ ${ }^{1}$ Universidade Federal do Triângulo Mineiro, Departamento de Engenharia Química \\ ${ }^{2}$ Universidade Federal do Triângulo Mineiro, Departamento de Engenharia de Produção \\ E-mail para contato: adjentina.lima@hotmail.com
}

\begin{abstract}
RESUMO - Água potável é essencial à vida, porém sua escassez é alarmante. Uma alternativa para minimizá-la é a utilização de destiladores solares para dessalinização de água salgada. Um destilador solar comum possui bacia plana e cobertura de condensação de declive único, entretanto, com a substituição dessa bacia por uma em formato de escada, configurando o destilador solar do tipo escada (DSE), estudos revelam aumento de produtividade de destilado. Logo, o objetivo deste trabalho foi o projeto e construção de um DSE baseada em dados da literatura visando à dessalinização de água salgada, bem como a análise de configurações e desempenho comparando-o com um destilador solar com cobertura piramidal (DSCP). O DSE construído é composto por bacia tipo escada com área superficial das bandejas de $0,5 \mathrm{~m}^{2}$, inserida em recipiente trapezoidal de vidro. Foram variadas a utilização de isolamento térmico e manutenção do nível de solução salina nas bacias dos destiladores e avaliadas as suas temperaturas e produtividade volumétrica. Os destiladores operaram concomitantemente e nas mesmas condições operacionais. Pôde ser observado em todos os experimentos que as temperaturas da bacia e cobertura do DSE foram maiores que as do DSCP. O DSE apresentou melhor desempenho que o DSCP, obtendo produtividades volumétricas em média $42,4 \%$ maiores. A água dessalinizada em todos os experimentos e ambos destiladores apresentaram salinidade inferior a 500mg. $\mathrm{L}^{-1}$, sendo própria ao consumo humano de acordo com a OMS.
\end{abstract}

\section{INTRODUÇÃO}

A água potável é essencial aos seres vivos e ao desenvolvimento da sociedade, porém sua escassez é verídica e alarmante. Apesar de mais de dois terços da Terra ser coberta por água, apenas 2,5\% correspondem à água doce e 97,5\% à água salgada (RAINHO, 1999). Sendo que a salinidade adequada da água para o consumo humano, segundo a OMS, é inferior a $500 \mathrm{mg} . \mathrm{L}^{-1}$ (ALVES, 2008). Tendo em vista esse cenário, a dessalinização da água salgada surge como uma tecnologia para remoção de sais a valores aceitáveis (FERNANDES, 2013).

Um dos métodos de dessalinização é a destilação solar. Um destilador solar simples é constituído por uma bacia plana de fundo preto fosco, na qual uma quantidade de água salgada ou salobra é utilizada como fluido de trabalho. Seu topo é formado por uma cobertura transparente inclinada, pela qual os raios solares são transmitidos e então absorvidos pelo fundo da bacia aquecendo a água e aumentando sua taxa de evaporação. $\mathrm{O}$ vapor de água ascendente é condensado quando entra em contato com a cobertura mais fria, eliminando sais, 
outros minerais e a maioria das impurezas, incluindo microrganismos nocivos à saúde (LOPES, 2013). Porém, destiladores solares apresentam baixa produtividade e eficiência.

A produtividade dos destiladores solares é afetada por fatores meteorológicos e por sua configuração. Como parâmetros meteorológicos não podem ser manipulados, a produtividade dos destiladores pode ser maximizada empregando-se algumas modificações em sua configuração, como a substituição da bacia plana por uma bacia subdividida em patamares, em formato de escada, configurando um destilador solar tipo escada (DSE).

Estudos comprovam que a produtividade de um DSE é aproximadamente 57\% mais elevada em relação à de um destilador solar simples (KABEEL, 2012). Isso ocorre, pois temperaturas mais elevadas são atingidas em seu interior, por haver maior área superficial para absorção e transferência de calor, além de a subdivisão da bacia em volumes de controle menores acarretar na diminuição do gasto energético para aquecimento da água (KABEEL et al, 2015).

A produtividade máxima do destilador tipo escada é alcançada para uma profundidade de salmoura nas bacias de $5.10^{-3} \mathrm{~m}$, largura de $12.10^{-2} \mathrm{~m}$, comprimento da bandeja de $2 \mathrm{~m}$, distância entre a superfície da água e a base da bandeja superior de $1.10^{-1} \mathrm{~m}$ (KABEEL, 2012).

Modificações nas geometrias das coberturas de condensação também apresentam elevação significativa na produtividade, como o aumento de faces expostas à radiação solar. Nesse sentido vale ressaltar o destilador solar com cobertura piramidal (DSCP), que possui quatro faces em sua cobertura de condensação (ARAÚJO et.al, 2015).

Logo, o trabalho em questão consiste na construção de uma unidade experimental de DSE utilizando materiais de baixo custo e fácil acesso, bem como, o estudo e avaliação do desempenho da unidade visando à dessalinização de água salgada e ao aumento de produtividade de destilado, além de comparar sua produtividade de destilado em relação a um DSCP, desenvolvido por Araújo et.al (2015), em diferentes condições operacionais.

\section{METODOLOGIA}

O destilador solar tipo escada foi projetado com base em dados literários (KABEEL, 2012). A unidade experimental é composta por uma bacia tipo escada de zinco galvanizado revestida com tinta preto fosco resistente a alta temperatura, com área superficial da base das bandejas de aproximadamente $0,5 \mathrm{~m}^{2}$. A bacia é composta por quatro bandejas com dimensões aproximadas de $12.10^{-2} \mathrm{~m}$ de largura, $1,05 \mathrm{~m}$ de comprimento e $5.10^{-3} \mathrm{~m}$ de profundidade. Posteriormente, foi inserida em um recipiente trapezoidal de vidro, que possuía uma cobertura com inclinação de aproximadamente $19^{\circ}$, semelhante a latitude da cidade de Uberaba, local onde o destilador solar operava, visando maior absorção de radiação solar (LOPES, 2013). Por meio de uma canaleta de vidro fixada na parede do destilador, a água dessalinizada, condensada sob sua cobertura era coletada e armazenada.

A cobertura de condensação do DSE era móvel para facilitar sua limpeza e manutenção. Para isso, uma borracha maleável foi aderida nas bordas da superfície interna da cobertura de condensação. Para pressionar a cobertura de vidro sobre o recipiente trapezoidal, evitando vazamentos, uma cantoneira de metal revestida de borracha era utilizada. 
A fim de minimizar perdas térmicas para o ambiente externo todas as paredes do destilador, exceto a cobertura, foram isoladas por uma camada mais interna de vidro, com 4 $\mathrm{mm}$ de espessura, e uma camada externa de $6 \mathrm{~cm}$ de poliestireno (isopor).

O DSCP era composto por uma bacia plana quadrangular de alumínio revestida de tinta preto fosco de área superficial de $2,025.10^{-2} \mathrm{~m}^{2}$ e cobertura piramidal de vidro de quatro faces, com inclinação de $19^{\circ}$, previamente desenvolvido por Araújo et al (2015). A água dessalinizada era coletada por canaletas e armazenada como no DSE.

As unidades experimentais de DSE e DSCP utilizadas são representadas na Figura 1.

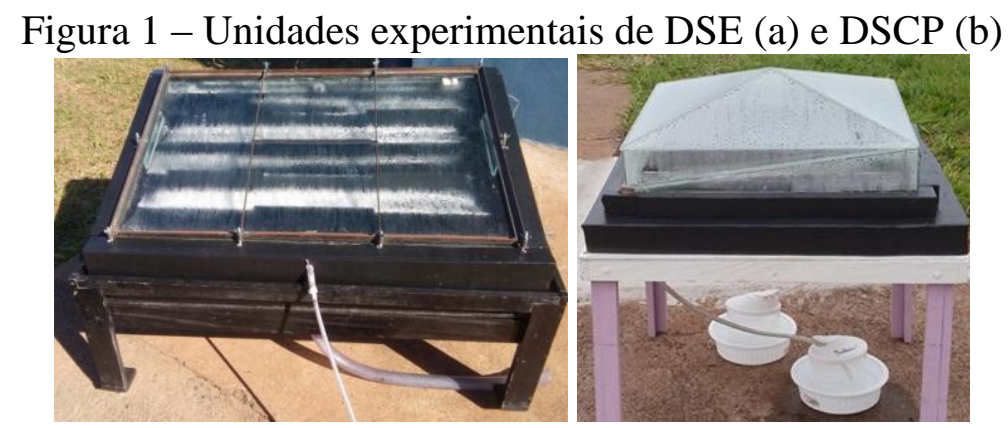

(a)

(b)

O fluido de trabalho a ser destilado tratava-se de uma solução com salinidade de 3,5\% (Massa de sal marinho culinário. Massa de água de torneira ${ }^{-1}$ ) e condutividade elétrica de

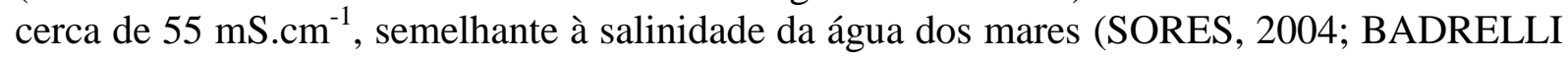
e VILLAS, 2013).

Os destiladores solares foram expostos à radiação solar das 10 ás 18 horas, concomitantemente e nas mesmas condições operacionais. Foram variados a utilização de isolamento térmico (isopor) e a manutenção do nível de $5.10^{-3} \mathrm{~m}$ de solução salina na bacia. Posteriormente, analisou-se a variação das temperaturas das coberturas e bacias dos destiladores, bem como a temperatura ambiente, as produtividades volumétricas por área da bacia em contato com a água salgada e a salinidade da água dessalinizada através de sua condutividade elétrica.

As temperaturas das bacias dos destiladores foram medidas utilizando termopares tipo $\mathrm{K}$, a produtividade volumétrica utilizando provetas graduadas e a condutividade elétrica por meio de condutivímetro de bancada Tecnopon® MCA 150.

\section{RESULTADOS}

Durante a operação da unidade experimental de DSE pôde-se perceber um bom isolamento proporcionado pela borracha aderida a superfície de condensação, evitando perda de vapor. Devido às altas temperaturas atingidas no interior do equipamento e a abrasividade da solução salina, a pintura da bacia do destilador sofreu desgaste.

O DSE pôde ser operado com êxito e seus resultados serem analisados em relação aos do DSCP. 
$\mathrm{Na}$ Tabela 1 estão contidas as produtividades volumétricas acumuladas dos destiladores após as oito horas de operação.

Tabela 1 - Produtividade volumétrica acumulada

\begin{tabular}{|c|cc|c|c|}
\hline \multirow{2}{*}{ Experimento } & \multicolumn{2}{|c|}{ Configuração } & \multicolumn{2}{c|}{ Produtividade $\left(\mathrm{L} . \mathrm{m}^{-2}\right.$ ) } \\
\cline { 2 - 5 } & Isolamento & Manutenção do nível & DSE & DSCP \\
\hline 1 & Sem & Sem & 4,294 & 3,259 \\
2 & Com & Sem & 4,396 & 3,605 \\
3 & Sem & Com & 3,428 & 2,252 \\
4 & Com & Com & 4,478 & 2,958 \\
\hline
\end{tabular}

As temperaturas das bacias, cobertura e ambiente em relação ao tempo estão dispostas na Figura 2.

Figura 2 - Variação das temperaturas ambiente, bacias e coberturas dos destiladores solares e produtividade volumétrica em relação ao horário para os experimentos $1,2,3$ e 4 .

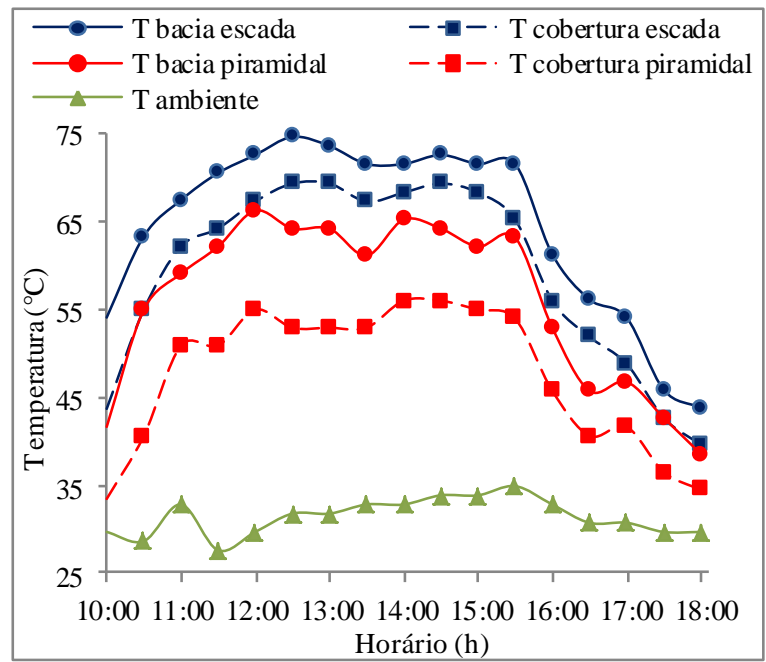

(a) Experimento 1

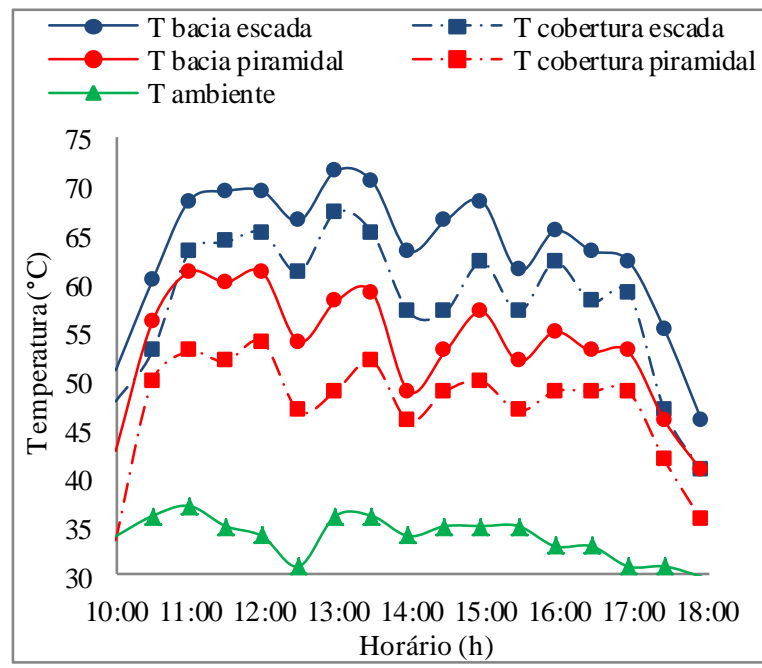

(c) Experimento 3

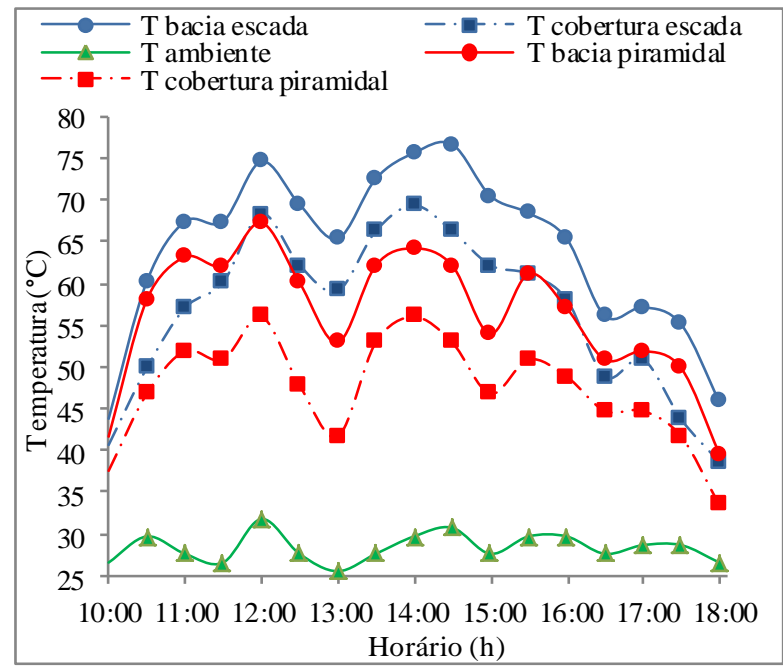

(b) Experimento 2

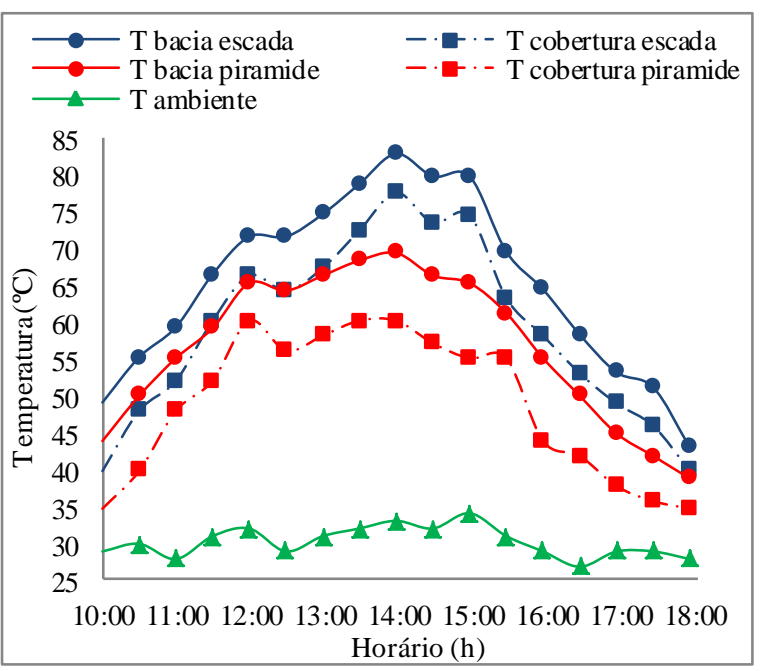

(d) Experimento 4 
Analisando a Tabela 1 e a Figura 2, verifica-se que para os experimentos 1, 2, 3 e 4 as produtividades volumétricas acumuladas por área da bacia do DSE foram, respectivamente, cerca de $44,03 \%, 21,94 \%, 52,22 \%$ e $51,39 \%$ maiores em relação ao DSC; também observouse que as temperaturas do DSE foram em média $8^{\circ} \mathrm{C}$ maiores que as do DSCP em todos os experimentos. Isso evidência um desempenho superior do DSE em relação ao DSCP independentemente da configuração. Tal fato é devido às temperaturas observadas da solução salina em sua bacia terem sido maiores do que as do DSCP. Isso é justificado, pois um volume menor de ar é retido no interior do destilador em relação ao DSCP, portanto, o aquecimento do ar aprisionado é acelerado. Também, deve-se ressaltar que a graduação da bacia oferece maior área superficial para absorção e transferência de calor em relação à bacia plana do destilador com cobertura piramidal e, consequentemente, uma elevação mais significativa da temperatura da água na bacia, o que proporciona um aumento na taxa de evaporação. A subdivisão da bacia em volumes de controle menores acarreta na diminuição do gasto energético para aquecimento da água, pois, quantidades menores de água serão aquecidas em cada patamar, se comparado ao volume total de uma bacia plana.

No trabalho teórico-experimental realizado por Kabeel et.al (2012), comparou-se a produtividade e a eficiência de um destilador solar de bacia plana com a de um DSE. A produtividade do DSE foi em média 57,3\% mais elevada em relação à do destilador simples, enquanto que no presente trabalho a produtividade foi cerca de 38,6\% mais elevada em relação a produtividade do DSCP. Isso é devido ao melhor desempenho de destiladores com cobertura piramidal em relação a destiladores simples, pois essa configuração favorece a absorção de radiação solar devido sua versatilidade quanto ao posicionamento ao sol e possui uma área de cobertura de condensação maior em relação à do destilador simples com uma única face de cobertura. Além disso, na cobertura piramidal, enquanto um dos lados recebe a incidência direta dos raios solares, os outros lados não recebem e consequentemente a temperatura nesses é menor, favorecendo a condensação do vapor ascendente.

Não se pode determinar a melhor configuração dos destiladores, devido aos testes terem sido realizados em condições climáticas distintas. Porém, apesar das temperaturas ambientes observadas durante o experimento 3 (sem utilização de isolamento térmico e com manutenção do nível) terem sido maiores que as do experimento 2 (com utilização de isolamento térmico e sem manutenção do nível), as produtividades volumétricas acumuladas dos destiladores para o experimento 2 foram maiores. Isso sugere que a utilização de isolamento térmico e não manutenção do nível maximizam o desempenho dos destiladores, visto que minimizaram perdas térmicas para o ambiente externo e a quantidade de calor necessária para o processo.

Para os dois destiladores a água coletada em todos os experimentos puderam ser classificadas como água da chuva (condutividade menor que $15 \mu \mathrm{S} . \mathrm{cm}^{-1}$ ) ou como água de rios de água doce (condutividade elétrica entre 0 e $800 \mu \mathrm{S} . \mathrm{cm}^{-1}$ ), sendo assim, pode-se inferir que todas as amostras de água tem salinidade menor ou igual a $0,05 \%$ ou $500 \mathrm{mg} . \mathrm{L}^{-1}$ (SORES, 2004; BADRELLI e VILLAS, 2013).

\section{CONCLUSÃO}

A unidade experimental de DSE pôde ser construída com matérias de fácil acesso e baixo custo. Por conseguinte, obteve-se êxito em sua operação, observando bom desempenho 
e produtividade de água dessalinizada. Em todas as configurações propostas o DSE apresentou melhor desempenho em relação ao DSCP devido a maiores temperaturas terem sido atingidas em seu interior, proporcionando maior taxa de evaporação e aproveitamento energético. A maior produtividade obtida para o DSE e DSCP foram de 4,478 L.m ${ }^{-2}$ e 3,605 L.m ${ }^{-2}$, respectivamente. A água destilada obtida em todos os experimentos, nos dois destiladores, apresentou salinada inferior a $500 \mathrm{mg} . \mathrm{L}^{-1}$, valor adequado para o consumo de acordo com a OMS.

\section{AGRADECIMENTOS}

Agradecemos o apoio financeiro provido pela FAPEMIG (PCE-00455-17) e UFTM.

\section{REFERÊNCIAS}

ALVES, R. S. Estudo sobre a dessalinização de águas salobras utilizando a energia solar. Monografia (Projeto de Graduação do curso de Engenharia Química) - Departamento de Engenharia Química, Universidade Federal de Uberlândia, Uberlândia, 2008.

ARAÚJO, B. S. A.; FARIA, É. V. de; ALVES, I. F. B.; BONTEMPO, L. H. da S.; OLIVEIRA, L. C. C. B.; LIMA, M. N.. Desenvolvimento e construção de um destilador solar para dessalinização de água salgada em diferentes concentrações de sais. Relatório (disciplina de Desenvolvimento de Processos Químicos II do Curso de Engenharia Química) - Departamento de Engenharia Química, Universidade federal do Triângulo Mineiro, Uberaba, 2015.

BANDERALI, M.;VILLAS, M. Como e porque medir a Condutividade Elétrica (CE) com sondas muiltiparâmetros?. Por Ag Solve. 2013. Disponível em: < https://www.agsolve.com.br/noticias/como-e-porque-medir-a-condutividade-eletrica-ce com-sondas-muiltiparametros>. Acesso em: 27 Jul. 2016.

FERNANDES, A. S. R. Adequabilidade da energia solar para a produção autónoma de água dessalinizada. Dissertação (Engenharia do Ambiente) - Instituto Superior de Agronomia - Universidade Técnica de Lisboa, Lisboa, 2013.

KABEEL, A.E. et. al. Theoretical and experimental parametric study of modified stepped solar still. Desalination. Tanta, 289 v., 12 -20, 2012.

KABEEL, A.E.; OMARA, Z.M.; YOUNES M.M. Techniques used to improve the performance of the stepped solar still: A review. Renewable and Sustainable Energy Reviews. Tanta, 46 v., $178-188,2015.14 p$.

LOPES, J. T. Dimensionamento e análise térmica de um dessalinizador solar tipo bacia com cobertura assimétrica. Tese (Doutorado em Engenharia Mecânica) - Programa de PósGraduação em Engenharia Mecânica, Universidade Federal de Uberlândia, Uberlândia. 2013.

RAINHO, J. M. Planeta Água, Educação. 221, v. 26, p. 48-64, 1999. 